\title{
Morpho-physiological Responses of Several Fescue Grasses to Drought Stress
}

\author{
Jianping P. Wang and Suleiman S. Bughrara' \\ Department of Crop and Soil Sciences, Michigan State University, East \\ Lansing, MI 48824 \\ C. Jerry Nelson \\ Division of Plant Sciences, University of Missouri, Columbia, MO 65211
}

Additional index words. Atlas fescue, tall fescue, drought tolerance, leaf elongation, leaf water content, leaf water potential

\begin{abstract}
Identification and screening of grasses with excellent drought tolerance is a desirable strategy in breeding drought-tolerant turf and forage cultivars. Not all fescue selections and cultivars may be equally drought tolerant. An Atlas fescue (Festuca mairei St. Yves) selection and three tall fescue (Festuca arundinacea Schreb.) cultivars-Barolex, Kentucky 31, and Falcon II-were subjected to increasing drought stress for a 12week period. Soil water content (SWC), leaf elongation ( $L E$ ), leaf water content (LWC), and leaf water potential $\left(\Psi_{w}\right)$ were measured weekly, and root length (RL) and biomass (RM) were recorded after 12 weeks. The SWC declined progressively during the 12-week drought treatment for all grasses. However, for the three tall fescue cultivars, the SWC decreased at a faster rate than for Atlas fescue. This indicated that Atlas fescue extracted soil water more slowly and developed less-intensive stress than the three tall fescue cultivars. The $L E$, $L W C$, and leaf $\Psi_{\mathrm{w}}$ decreased in drought-treated plants of all grasses; nevertheless, the values for the Atlas fescue remained similar to control plants for a longer period of time than the values for the three tall fescue cultivars. Drought stress significantly reduced root biomass and root length of the grasses. These four Festucas avoid drought stress through changes in leaf and root morphology and probably through osmotic adjustment to maintain sufficient turgor pressure in the growing zone for leaf elongation. The slower decrease in LE, LWC, and leaf $\Psi_{w}$ for Atlas fescue during the drought-stress period suggested greater drought tolerance and the potential value for improving this character in a breeding program.
\end{abstract}

Over one-half of the world's land surface is exposed to periodic drought (Boyer, 1982) causing it to be a major limiting factor for the growth of cool season grasses in transitional and warm climatic regions. In urban environments, drought stress is exacerbated by negative soil factors as well as elevated temperatures (Cregg, 1995). As a result of below-optimal water supply, turfgrass quality and forage yield often are reduced. Usually, as water conservation becomes an important public issue, water for landscape and agronomic irrigation is restricted. This suggests identification and screening of grasses for genetic improvement of drought tolerance and reduced water use may be a desirable strategy.

In general, drought resistance is the capacity of a plant to survive or grow during drought. Mechanisms of resistance have been classified into drought escape, drought avoidance, and drought tolerance (Jones et al., 1981). Escape mechanisms are related to rapid phenological development whereby

Received for publication 15 Sept. 2006. Accepted for publication 12 Dec. 2007.

${ }^{1}$ To whom reprint requests should be addressed; e-mailbughrara@msu.edu become quiescent or dormant during prolonged drought. They temporarily suspend visible growth of meristems, such as basal buds, to avoid drought damage and allow survival (McWilliam, 1968).

Grass genotypes and cultivars vary in their responses to drought stress, which involve changes in morphological and physiological factors (Wu and Huff, 1983). Knowledge of relative involvement of each morphological and physiological characteristic in drought tolerance is important in selecting grass genotypes to facilitate breeding of drought-tolerant cultivars.

Tall fescue, a popular turfgrass and forage species in cool and transition zone regions, originated from North Africa and has been recognized for its exceptional drought tolerance (Fry and Butler, 1989; Norris and Thomas, 1982). Turfgrass cultivars vary in drought resistance (Carrow, 1996; White et al., 1992), and 'Kentucky 31' and 'Falcon II' have been identified as having good drought tolerance (Huang, 2001; Huang and Gao, 1999). 'Barolex' is a new tall fescue forage-type cultivar, and its drought tolerance is unknown. Atlas fescue species are found only in the Atlas Mountain ranges of northwest Africa. There is no definitive report on drought tolerance of Atlas fescue, although it has xerophytic adaptation to survive long, dry summers in the Mediterranean climate (Marlatt et al., 1997). In the current study, we sought to investigate drought responses of a selection of Atlas fescue (Festuca mairei) compared with three tall fescue ( $F$. arundinacea Schreb.) cultivars: Kentucky 31, Falcon II, and Barolex.

Objectives of this study were to compare leaf elongation, leaf water content, leaf water potential, root biomass, and root length of a selection of Atlas fescue with Barolex, Kentucky 31, and Falcon II tall fescue cultivars. Drought stress was imposed for 12 weeks with the goal of investigating drought response of Atlas fescue compared with tall fescue cultivars.

\section{Materials and Methods} (Mecully, 1999; Weerathaworn et al., 1992 and adapted leaf characteristics, such as lower specific leaf area and lower stomatal density that reduce water loss, are examples. Physiological adaptations related to water conservation are reduced stomatal conductance (rapid stomatal closure) and low transpiration rates to reduce water loss (Jones et al., 1981). Drought tolerance at low tissue water potential is achieved by maintenance of regular physiological processes often associated with osmotic adjustment.

Plant growth under drought stress is substantially reduced, partly because lower turgor pressure in cells affected by low water potential results in a slower cell expansion rate (Pattanagul and Madore, 1999). The osmotic adjustment in response to water deficit can result in maintenance of water uptake to enhance turgor and maintain cell elongation (Begg and Turner, 1976) and leaf elongation (Hsiao, 1973). Dormancy can also be a mechanism by which perennial grasses
Plant materials and drought treatment application. Four Festuca grasses-a selection of Atlas fescue originally collected from Morocco and three commercial tall fescue cultivars for turf and forage (Barolex, Falcon II, and Kentucky-31) - were used in this experiment. The upper fully developed leaves from each pot of the drought-stressed plants were detached weekly for leaf water content (LWC) measurement. The cultivars included in this study have been tested and were found to be endophyte-free. A single tiller of each entry was used to vegetatively propagate a mature donor plant in the greenhouse. From each plant, two vegetative tillers were transplanted into each of six PVC tubes (100 $\mathrm{cm}$ deep $\times 10.8 \mathrm{~cm}$ diam.). The tubes had been lined with a sleeve of heavy-duty plastic to facilitate moving the root system and soil from the tube at the end of the experiment. Tubes were filled with the same 
weight $(11.8 \mathrm{~kg})$ of a recommended substrate for athletic fields consisting of $85 \%$ sand and $15 \%$ (by volume) field soil. The transplanted tillers were allowed to become established for 15 weeks in the greenhouse during fall with natural lighting, regular irrigation, fertilizer, and trimming. Greenhouse temperature was $25 \pm 3{ }^{\circ} \mathrm{C}$, with average 13 -h photoperiod.

After the plants were trimmed to leave a stubble of $7.5 \mathrm{~cm}$, a preconditioning drought was applied by withholding water for 2 weeks. Plants were allowed to recover by irrigating for 1 week before trimming again to $7.5 \mathrm{~cm}$. Then, three tubes of each entry were randomly allocated to the drought treatment and the control. Drought stress was gradually imposed by progressively applying decreasing amounts of water from 200 $\mathrm{mL} \cdot \mathrm{d}^{-1}$ for week 1 (up to $100 \%$ soil capacity in the tube), to 150,100 , and $50 \mathrm{~mL} \cdot \mathrm{d}^{-1}$ for weeks 2, 3, and 4, respectively. Water was not applied during the remainder of the 12-week drought period. Control plants were irrigated regularly during this period. The PVC tubes were re-randomized weekly during this drought period to minimize effects of possible environmental gradients within the greenhouse.

Soil water content measurement. The PVC tubes were weighed every week at the same time (1:00 PM) to determine gravimetric soil water content (SWC) from water loss. The mass of soil mixture was measured for each tube at the beginning of the experiment, which also ensured the same weight of substrate $(11.8 \mathrm{~kg})$ in each tube. The moisture of the soil mixture was estimated by weighing 10 samples, first fresh and then after ovendrying at $80^{\circ} \mathrm{C}$.

Leaf elongation measurement. After 15weeks' establishment, three tillers in each tube were randomly chosen and labeled with wires of different color. The lengths of the top two emerging leaves on each tiller were measured from the tip of each lamina to the ligule of the next oldest leaf (Norris and Thomas, 1982) every week until the leaf growth of the drought-stressed plant ceased.

Leaf water content measurement. An upper fully developed leaf of the droughtstressed plants was detached weekly for leaf water content (LWC) measurement. Control plants were sampled in weeks 3,6 , and 9 during the drought period. The fresh weight (FW) (weight of the leaf immediately after detachment), turgid weight (TW) (weight of the leaf after soaking in MiniQ water for $24 \mathrm{~h}$ at room temperature), and dry weight (DW) (weight of the leaf after oven drying at $80^{\circ} \mathrm{C}$ for $24 \mathrm{~h}$ ) of the leaf were measured. Relative LWC was calculated according to Slavik (1974) and White et al. (1993) as LWC (\%) = $(\mathrm{FW}-\mathrm{DW}) /(\mathrm{TW}-\mathrm{DW}) \times 100$.

Leaf water potential measurement. All plants were covered by a black plastic sheet in the evening to imitate a predawn condition (closed stomata and low respiration). The following morning, duplicate fully emerged, undamaged leaf blades in each tube were sampled and leaf water potential $\left(\Psi_{\mathrm{w}}\right)$ was measured immediately using a pressure chamber (Soil Moisture Equipment Corp., Santa Barbara, CA). The weekly measurements were conducted in the greenhouse at 22 to $25^{\circ} \mathrm{C}$. Data were eliminated when the leaf $\Psi_{\mathrm{w}}$ of the control was greater than -0.6 MPa.

Root length and biomass measurement. At the end of the experiment, the heavy-duty plastic sleeve, soil, and root system were taken out of each tube. The soil substrate was gently removed from the root system by flowing water. Length of the root system RL (root depth) was measured using a ruler. Root biomass (RM) was weighed after blotting dry with a paper towel and air-drying at room temperature for about $6 \mathrm{~h}$ to remove surface moisture.

Statistical analyses. The data of LE, LWC, SWC, and leaf $\Psi_{\mathrm{w}}$, were subjected to analysis of variance (ANOVA), using repeated measurements in time with SAS software (SAS Institute, 2003). Comparisons were made within the four entries by one-way ANOVA and between drought and control treatments by the Student's $t$ test in each week. Mean separations were performed by a least-significant difference (LSD) procedure where the $F$ value was significant at the $P=$ 0.05 level. Data for RL and RM were subjected to one-way ANOVA to compare within the four entries and between stressed and control plants. Relationships between parameters were fitted to appropriate nonlinear regression models using Microsoft Excel (Microsoft Co., Redmond, 2002).

\section{Results}

The ANOVA analysis of all the measurements showed that differences among treatments, entries, and time (weeks) were highly significant $(P<0.0001)$. The interaction of treatment $\times$ entry, treatment $\times$ time, entry $\times$ time, and treatment $\times$ entry $\times$ time were all significant $(P<0.0001)$. The differences were dissected based on time and treatments to thoroughly compare the grass response to drought treatment in leaf elongation, leaf water content, leaf water potential, and soil water content.

Soil water content and leaf water potential. When the experiment began at full water capacity, the SWC was $9.33 \%$. Starting at week 2 of the drought treatment, SWC declined significantly $(P<0.001)$ (Fig. 1). The rate of soil water depletion was similar among the grasses with the exception of Atlas fescue, which was slower. Specifically, from week 4 to 8 , SWC of Atlas fescue was significantly higher than the other entries, indicating that it extracted less soil water.

The imposed drought stress had a significant effect on leaf $\Psi_{w}$, an indicator of plant stress of the grasses studied. In the control plants, leaf $\Psi_{\mathrm{w}}$ was similar $(P=0.086)$ among the grasses and remained relatively high across the 12-week period (Fig. 2). By contrast, in stressed plants leaf $\Psi_{\mathrm{w}}$ showed significant differences from the control after 4 (for 'Falcon II'), 5 (for 'Kentucky 31'), 6 (for 'Barolex'), or 8 (for Atlas fescue) weeks. In addition, leaf $\Psi_{\mathrm{w}}$ of stressed plants decreased differently among the four grasses. Atlas fescue maintained leaf $\Psi_{\mathrm{w}}$ at the level of control plants longer during the drought period than did the other three cultivars. Variation of leaf $\Psi_{\mathrm{w}}$ was highly dependent on SWC (Fig. 3) with a similar pattern for the four grasses, i.e., leaf $\Psi_{\mathrm{w}}$ gradually decreased but remained below $-1 \mathrm{MPa}$ as SWC decreased from $9.33 \%$ to about $2.8 \%$. The results reflected that soil water was readily available and sufficient for the plants in the SWC range from $9.33 \%$ to $2.8 \%$. The critical SWC of $2.8 \%$ was basically in agreement with the threshold of SWC for initial stomatal closure due to drought stress in tobacco (Nicotiana tabacum L.) (Riga and Vartanian, 1999). The three tall fescue cultivars showed

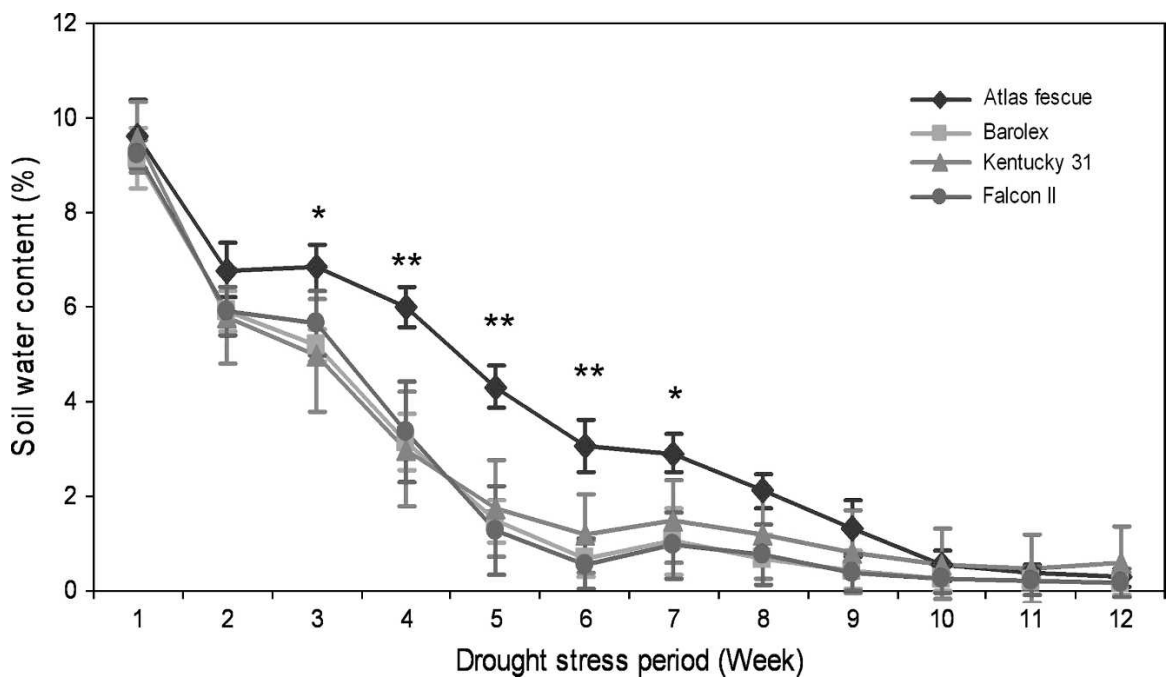

Fig. 1. Soil water content during the drought-stress period. Error bars indicate standard errors (SE). *, **Significantly different means among the stressed plants of four grasses at certain weeks at $P \leq$ 0.05 and 0.01 , respectively. 


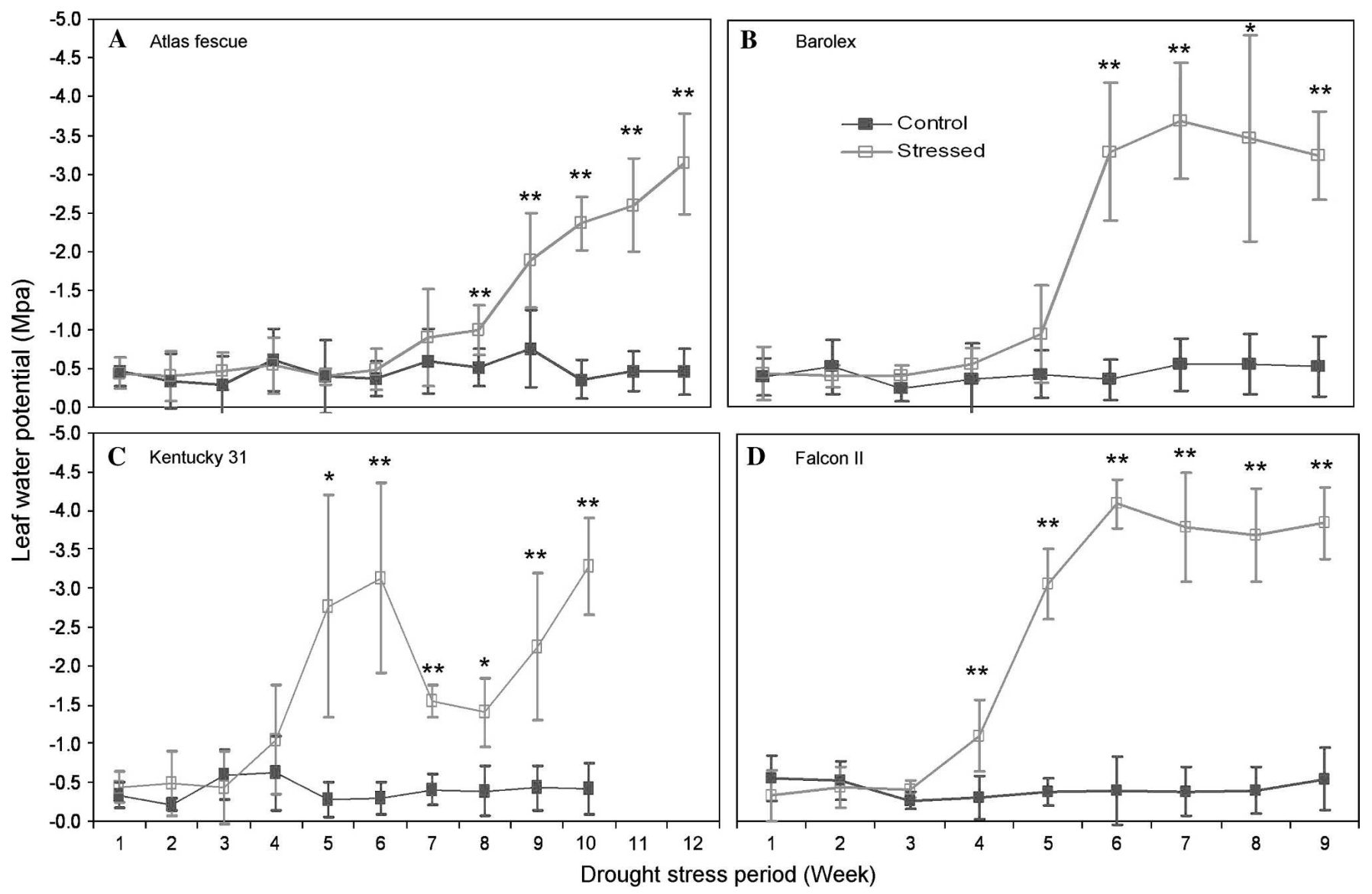

Fig. 2. Leaf water potential during the drought-stress period. Error bars indicate standard errors (SE). *,**Significantly different means between control and stressed plants at certain weeks at $P \leq 0.05$ and 0.01 , respectively.

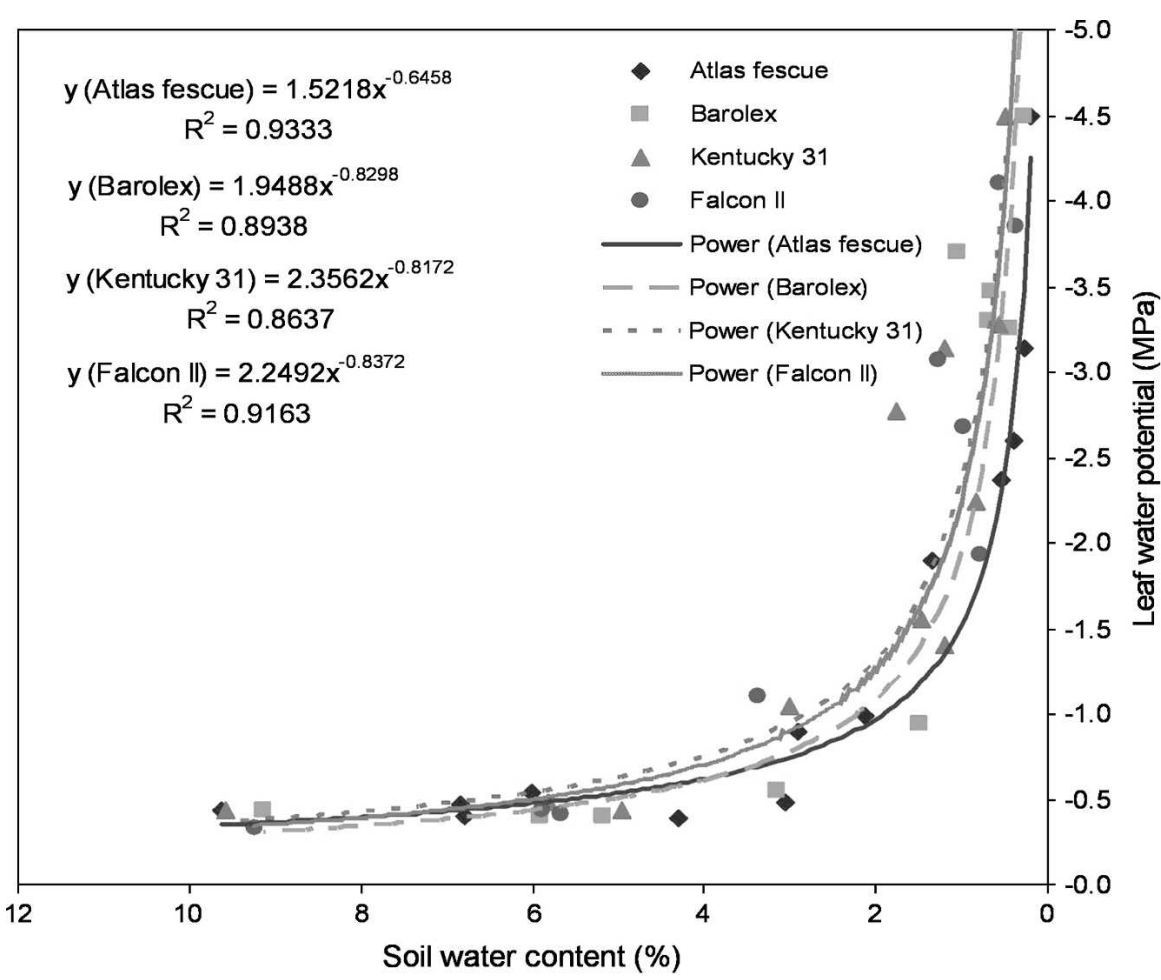

Fig. 3. Relationship between soil water content and leaf water potential. a more rapid decrease in leaf $\Psi_{\mathrm{w}}$ as the soil dried below a SWC of $1.5 \%$ to $1.8 \%$, whereas leaf $\Psi_{\mathrm{w}}$ of Atlas fescue did not decrease steeply until SWC was near $1 \%$. This suggests Atlas fescue is less sensitive to soil water deficits than the other three cultivars.

Leaf elongation rate. Atlas fescue had lower LE than 'Barolex' and 'Kentucky 31' in the first week (Fig. 4). As the stress gradually increased, there was a negative effect on LE of all grasses $(P<0.001)$ when compared with the control (Fig. 5). However, the mean LERs were similar for the control Atlas fescue, 'Barolex', and 'Kentucky 31' across the 12-week period and significantly greater than that of 'Falcon II' (Fig. 4). These results were indicative that the control 'Falcon II' grew relatively slower than other grasses, and Atlas fescue initially had a low LE but it increased in later weeks during the experimental period (Fig. 5).

Between weeks 8 and 10, LE of the control plants was greater than the first 7 weeks of the drought treatment period. At week 10, LE of the control plants of 'Kentucky 31' dropped dramatically when the plants started to bloom and vegetative growth was switched to reproductive growth. By contrast, in drought-treated plants, when comparing across the whole drought-stress period, the average LE for four grasses was not significantly different $(P=0.5078)$. 
However, when comparing drought-stressed with control plants, the LE of the three stressed tall fescue cultivars started to decrease to below the level of the control plants at week 5 or 6 , whereas for Atlas fescue, LE started to decrease at a later time, at week 7, of stress. The LE of droughttreated plants in 'Barolex' and 'Falcon II' ceased after 9 weeks of treatment, while in Atlas fescue and 'Kentucky 31', LE lasted longer, up to week 10 .

The relation between LE and SWC was fitted to a second-order polynomial function (Fig. 6). When SWC was near full soil capacity ( $8 \%$ to $9.33 \%)$, the LE of 'Barolex' and 'Kentucky 31' was higher than those of

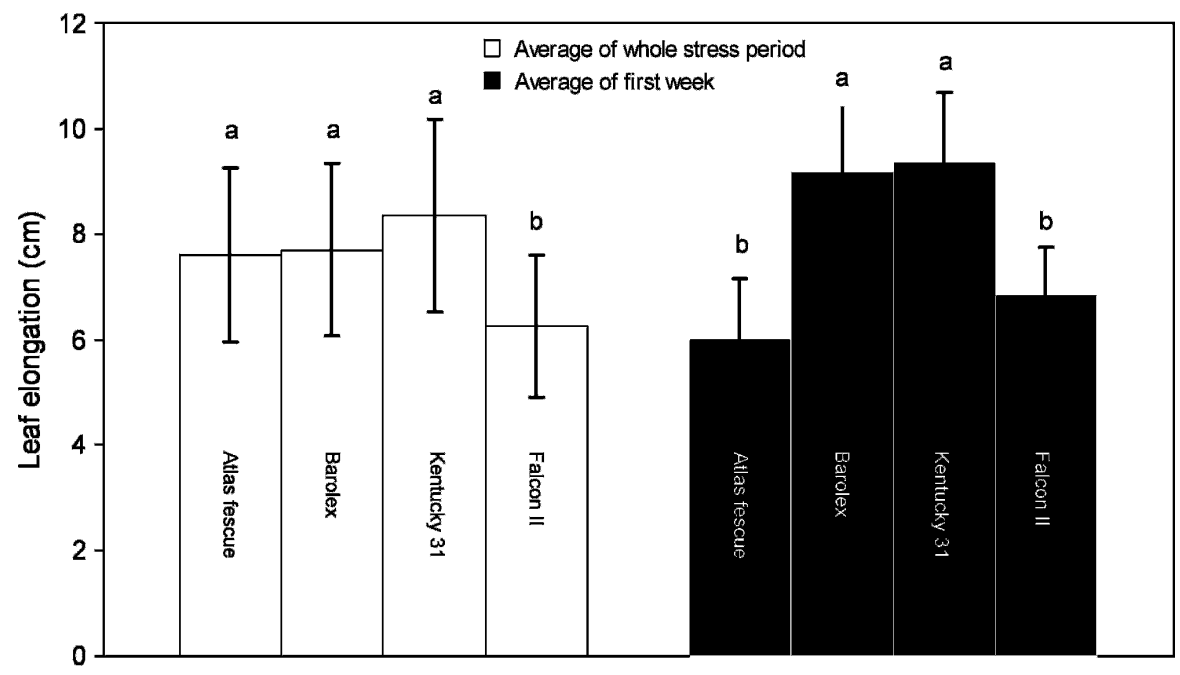

Fig. 4. Leaf elongation of the treatment control plants during the drought period. Columns with the same letter indicate no significant differences among them at $P \leq 0.05$. Error bars indicate standard errors (SE).
'Falcon II' and Atlas fescue, indicating that 'Barolex' and 'Kentucky 31' were growing faster at a high SWC. As the SWC was declining, LE decreased differently among the four grasses. 'Falcon II' and Atlas fescue showed a relatively slow decreasing rate compared with 'Barolex' and 'Kentucky 31' because the slopes of trend line for 'Falcon II' and Atlas fescue were less steep, suggesting that the growth of 'Falcon II' and Atlas fescue was less sensitive to declining SWC.

The LE responded to the decreasing leaf $\Psi_{\mathrm{w}}$ following a polynomial function (Fig. 7). As leaf $\Psi_{w}$ was declining and becoming more negative, the LE decreased for all grasses, but at different rates. The decrease in rate of LE of Atlas fescue and 'Falcon II' was less than that of 'Barolex' and 'Kentucky 31', indicating that, on a relative basis, LEs of Atlas fescue and 'Falcon II' were less sensitive to the increasing severity of drought stress.

Leaf water content. Drought-stress treatment had a significant $(P<0.001)$ effect on LWC of the grasses. The LWC of the control plants remained constant at about $87.7 \%$ during the whole experimental period (Fig. 8). In plants subjected to drought, LWC decreased differently among the four grasses. For the tall fescue cultivars, LWC of stressed plants was at the level of the control plants during the first 3 or 4 weeks of growth, whereas for Atlas fescue, LWC of stressed plants maintained the same level as the

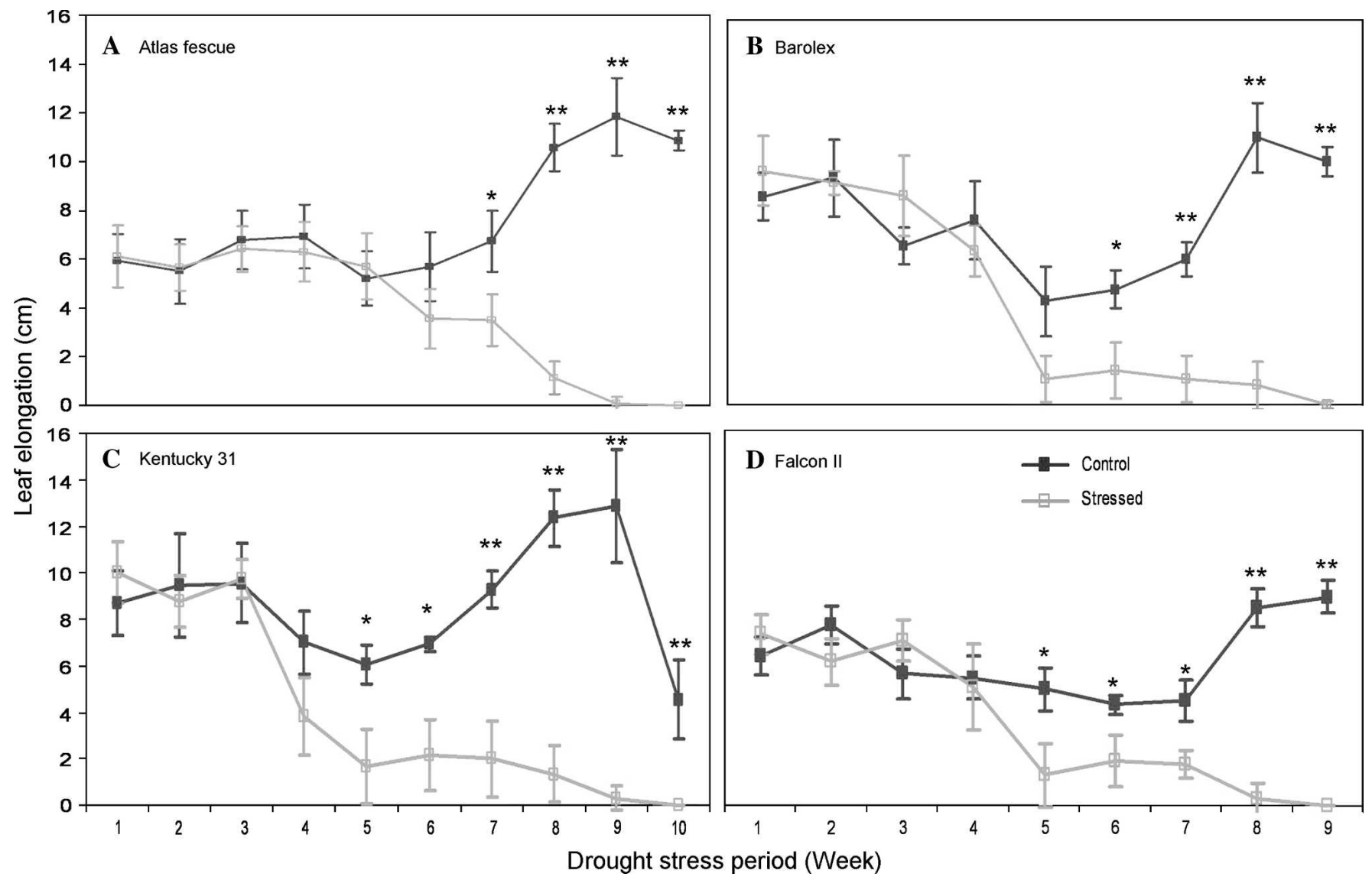

Fig. 5. Leaf elongation during the drought-stress period. Error bars indicate standard errors. $* * *$ Significantly different means between control and stressed plants at certain weeks at $P \leq 0.05$ and 0.01 , respectively. 


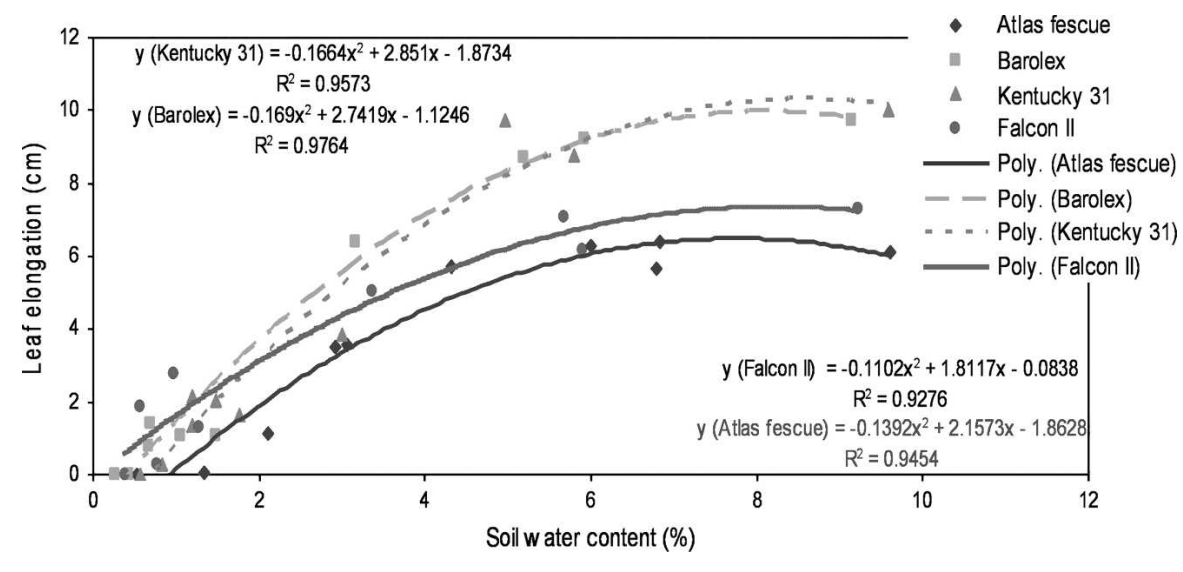

Fig. 6. Relationship between leaf elongation and soil water content.

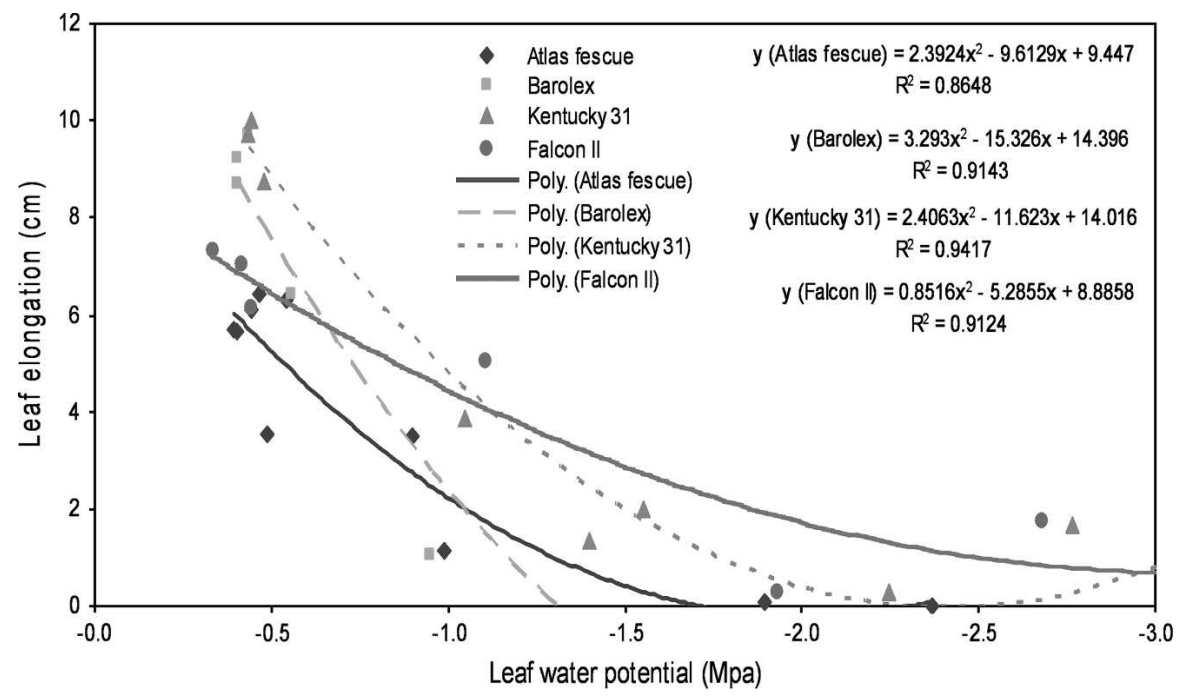

Fig. 7. Relationship between leaf elongation and leaf water potential.

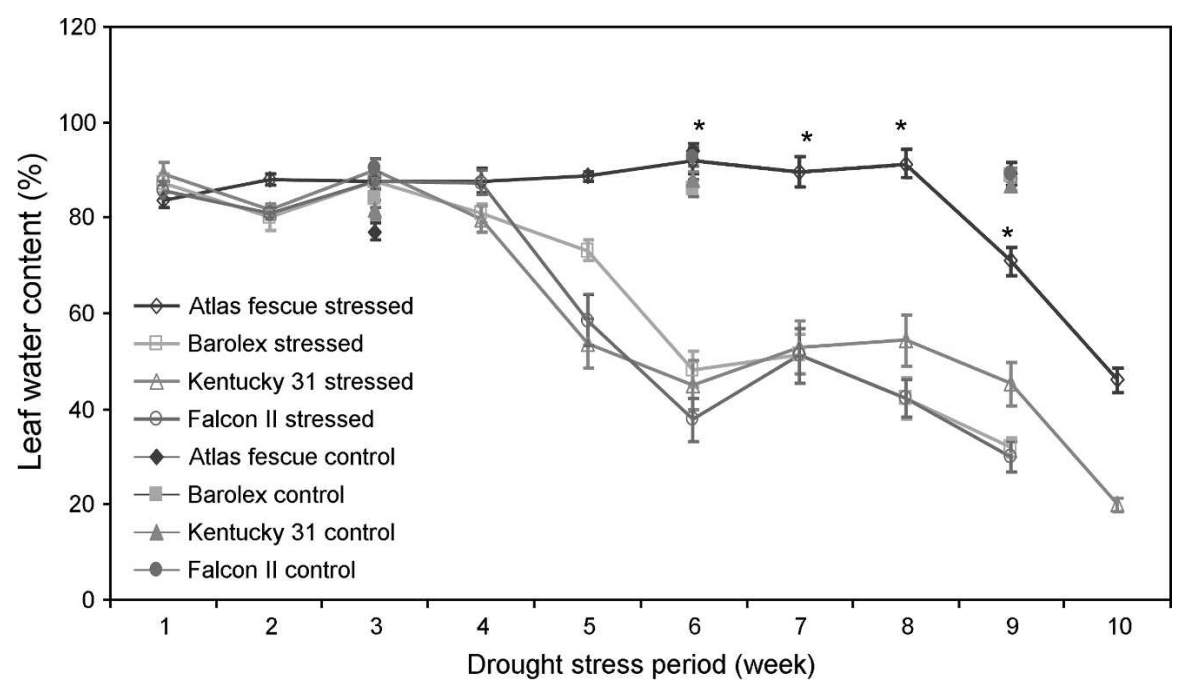

Fig. 8. Leaf water content during the drought-stress period. Error bars indicate standard errors (SE). *Significantly different means among the stressed plants of four grasses at certain weeks at $P \leq 0.05$.

control plants up to 8 weeks. The LWC of Atlas fescue was significantly higher than that of the cultivars between weeks 6 and 9 in the drought-stress treatment. The results imply that Atlas fescue may accumulate or conserve water in leaf tissue and maintain turgor as a stress-avoidance mechanism through adapted leaf and root morphology.

The relationship of LWC in response to SWC showed three stages (Fig. 9). When
SWC was high ( $8 \%$ to $9.33 \%)$, LWC of all grasses was maintained at a high level (between $80 \%$ and $90 \%$ ). In the second stage, as SWC decreased from $8 \%$ to about $4 \%$, LWC showed a slightly increasing trend, moreso in Atlas fescue than in the cultivars. In the third stage, when the SWC was decreasing from $4 \%$ to near $0 \%$, the LWC decreased dramatically for all the grasses. It was notable, however, that with SWC decreasing from $6 \%$ to $2 \%$, a medium drought-stress status, LWC of Atlas fescue remained higher than that of the other grasses and then decreased rapidly.

The association of LWC with leaf $\Psi_{\mathrm{w}}$ is described by a polynomial function in Fig. 10. As leaf $\Psi_{\mathrm{w}}$ became more negative, specifically between -1 and $-2.5 \mathrm{MPa}$, the LWC of grasses declined but at a much slower rate for Atlas fescue than the cultivars, especially between leaf $\Psi_{\mathrm{w}}$ of -1.2 and -2.4 $\mathrm{MPa}$. This again suggested that Atlas fescue had an adaptation ability to accumulate or conserve water in leaf tissue under drought stress.

Root length and biomass. The RL among grasses ranged from 115 to $132 \mathrm{~cm}$ and varied significantly $(P=0.034)$. 'Barolex' had the longest root system, while 'Kentucky 31 ' had the shortest (Fig. 11A). The RL of 'Falcon II' was negatively affected by drought treatment, whereas there was no significant difference in RL between the control and drought-treated plants of Atlas fescue, 'Barolex', and 'Kentucky 31'. No significant difference was found in RM among the grasses when the control and drought-stress treatments were averaged $(P=0.072)$. However, the drought treatment had a significant $(P=0.003)$ effect on RM. Stressed plants of Atlas fescue, 'Barolex', and 'Falcon' had significantly less RM than did their controls but not 'Kentucky 31' (Fig. 11B). Results suggested that control plants of 'Barolex' and Atlas fescue with longer roots might be more adaptive to drought stress than 'Kentucky 31'. However, the RM of 'Kentucky 31' was not reduced by severe drought stress, suggesting that 'Kentucky 31' may tolerate the drought stress through maintenance of viable roots capable of extracting available soil water, even though it had a shorter root.

\section{Discussion}

Understanding drought-tolerance mechanisms in grass species and the genetic variation among genotypes would guide breeding and management programs in improving performance under drought stress. Several mechanisms have been implicated in causing differences in drought tolerance of plants (Jones et al., 1981; Levitt, 1972). Unlike annual plants that can escape drought by maturing before stress becomes severe, perennial grasses cannot escape drought completely by early flowering. During this study, some control plants but not drought-stressed plants flowered, indicating these grasses did not escape drought by earlier maturity. In fact, the 


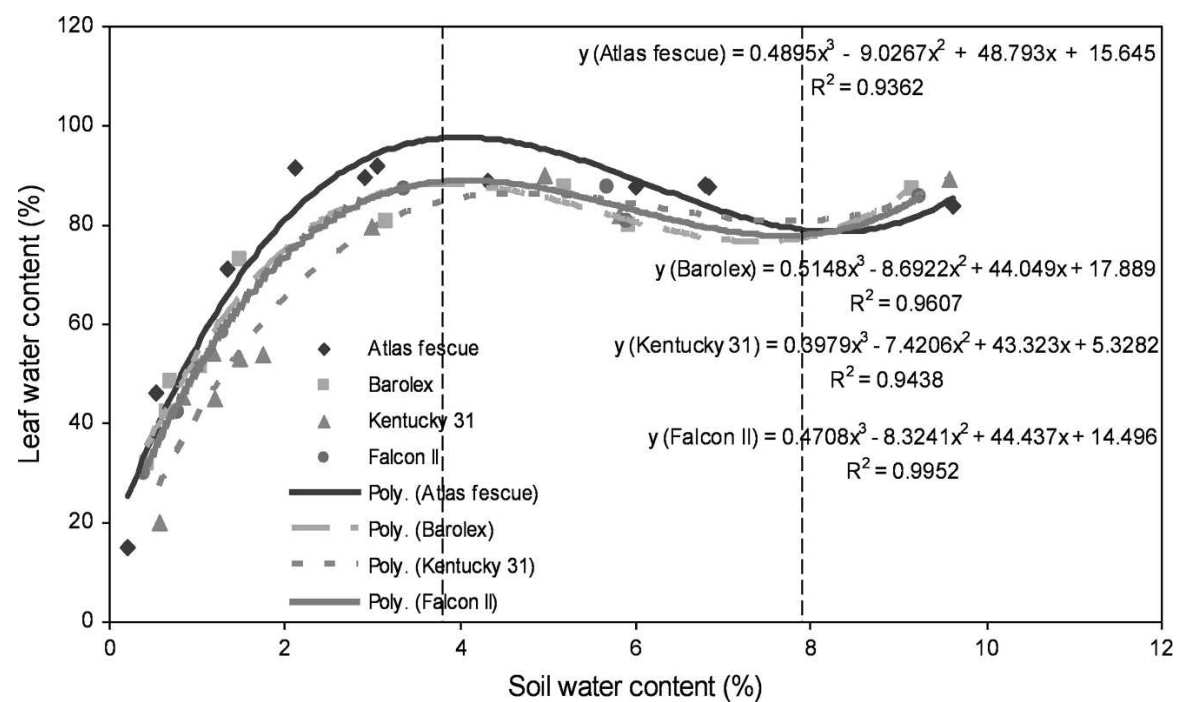

Fig. 9. Relationship between soil water content and leaf water content.

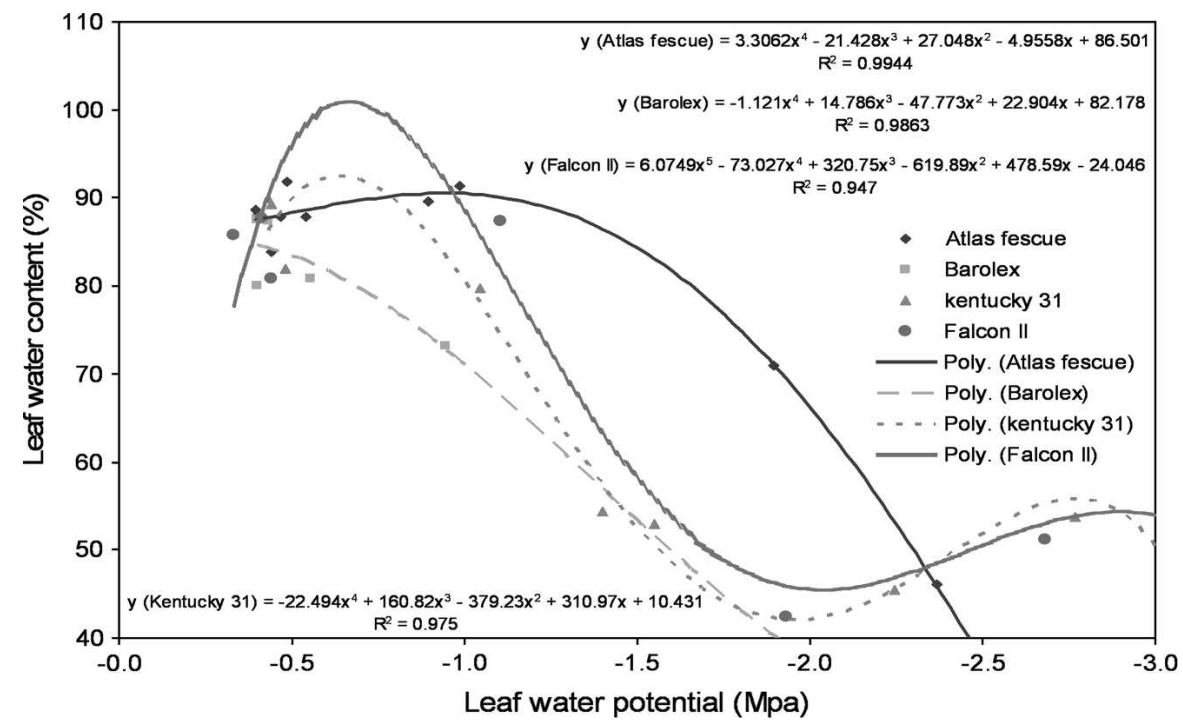

Fig. 10. Relationship between leaf water potential and leaf water content.

opposite occurred, as reproductive growth was inhibited by the imposed drought stress.

All four grasses maintained leaf elongation until low SWC of $1.2 \%$ (Figs. 1 and 5), indicating that they remain active rather than dormant during the drought-stress period. We observed that leaves of all the grasses rolled initially, and as SWC decreased further, the leaf tip showed firing and lower leaves became bleached. These symptoms suggested these grasses may employ a similar strategy to reduce the transpiration surface area and close stomata to limit plant water loss.

In an earlier study, tall fescue relied primarily on an extensive root system for drought tolerance (Qian et al., 1997) because the longer root system had greater volume and surface areas of roots in contact with soil to facilitate water and nutrient uptake under drought stress. The root system has been chosen as a selection trait in breeding pro-
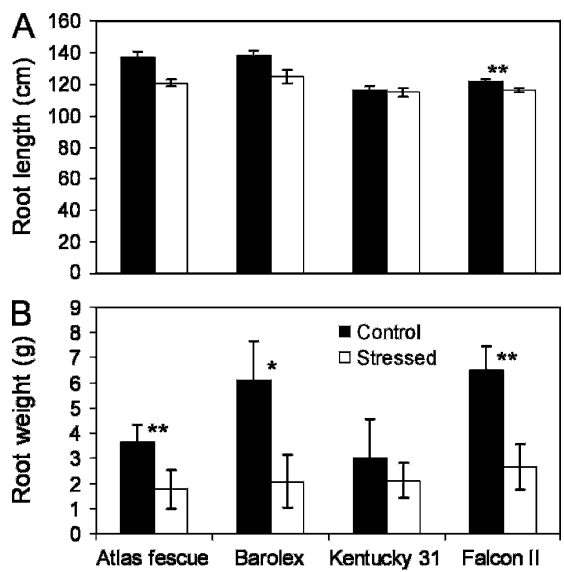

Fig. 11. Root length and biomass comparisons of treatment control and stress-treated plants. Error bars indicate standard errors. Bars with the same letter indicate there are no significant differences among the means of cultivars at $P \leq 0.05$. * ** Significantly different means between control and stressed plants in certain cultivar at certain weeks at $P \leq 0.01$.

tribute to drought tolerance of plants (Aussenac et al., 1989).

During water stress, numerous physiological functions are affected before the leaves show signs of wilting. However, cell expansion is the most sensitive trait (Boyer, 1988) and is reduced by drought before other physiological processes (Wardlaw, 1969). In this study, LE was measured weekly during the drought-stress period as a major indicator of the status of plant response to drought. Notably, for Atlas fescue and 'Kentucky 31', LE declined significantly even 1 week earlier than leaf $\Psi_{w}$, which has been shown to be an effective measurement of the maximum soil water potential available to roots (Tardieu and Simonneau, 1998) (Figs. 2 and 5). The results confirmed that LE is a sensitive parameter for drought-tolerance evaluation in plants. In addition, it is difficult to make measurements of leaf $\Psi_{w}$ on severely drought-stressed leaves, but LE could be measured at any time and situation.

Cell expansion directly contributes to the leaf elongation because reduced leaf growth is mainly caused by a decrease in turgor pressure of enlarging cells (Matyssek et al., 1988). Osmotic adjustment may enable leaves to maintain sufficiently high turgor pressure in the growing zone to maintain the leaf elongation. The LE of 'Falcon II' and Atlas fescue declined more slowly as the SWC and leaf $\Psi_{\mathrm{w}}$ were decreasing (Figs. 6 and 9), suggesting that osmotic adjustment may play a role in maintaining the turgor pressure necessary for LE, which is the resistance mechanism employed by the grass to resist drought stress. Osmotic potential of the drying leaves should be considered as an indicator.

The LE and LWC data (Figs. 5 and 8) showed that Atlas fescue maintained leaf growth and regular LWC longer than the other three grasses. Maintenance of growth and LWC of Atlas fescue may have resulted 

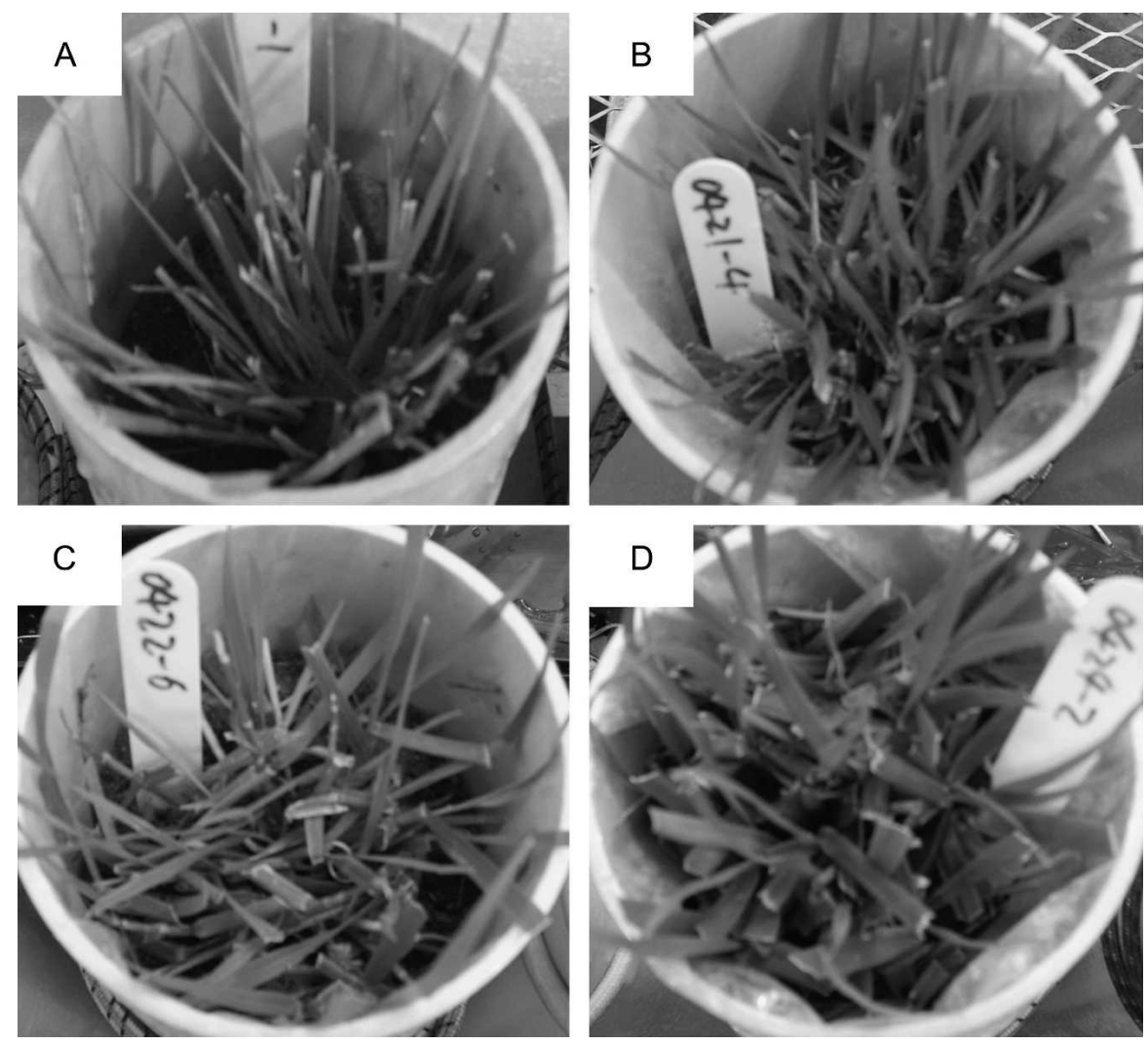

Fig. 12. Phenotype of the Atlas fescue (A), Barolex (B), Kentucky 31 (C), and Falcon II (D) cultivars before imposing drought stress.

due to a relatively low rate of water use by Atlas fescue. In studies with container-grown plants, dry-down responses are often confounded with plant size (Graves et al., 2002). Smaller sized plants may not evaporate sufficient water to cause severe stress. Therefore, SWC and leaf $\Psi_{\mathrm{w}}$ may decline slower in large plants, regardless of their relative drought tolerance. However, in our study, plant size was controlled to be the same by establishment for 15 weeks and trimming to same height (Fig. 12).

To evaluate possible effects of plant size or rapidity of stress development on leaf water loss and reduced leaf growth, a regression analysis was performed between LE and LWC versus SWC (Figs. 6 and 9) and leaf $\Psi_{\mathrm{w}}$ (Figs. 7 and 10), respectively. Results suggested that 1) LE of Atlas fescue and 'Falcon II' were less sensitive to the drought stress than 'Barolex' and 'Kentucky 31' as SWC and leaf $\Psi_{\mathrm{w}}$ were decreasing (Figs. 6 and 9). In addition, 2), a mechanism may exist in 'Falcon II' and Atlas fescue to maintain the cell turgor necessary for cell expansion as SWC was declining and leaf $\Psi_{\mathrm{w}}$ was becoming more negative, and 3) all the grasses tended to accumulate more water as drought stress increased, perhaps due to a signal from the roots. Atlas fescue appeared more sensitive than the cultivars to the signal and more capable of accumulating water in the leaf tissue (Figs. 7 and 9). This was also evident 4) as Atlas fescue had a greater ability to accumulate water in leaf tissue under severe drought stress (at leaf $\Psi_{\mathrm{w}}=-1.2$ to $-2.4 \mathrm{MPa}$ ) (Fig. 10). Atlas fescue consumed less volume of soil water between weeks 4 and 8 of drought stress (Fig. 5) but maintained a higher LE and LWC (Figs. 5 and 8) than the cultivars, further indicating its efficient water use and expression of drought tolerance.

In summary, drought stress reduced LE, LWC, leaf $\Psi_{\mathrm{w}}$, root biomass, and root length of the grasses. These Festuca spp. avoid drought stress through changes in leaf and root morphology and probably through osmotic adjustment to maintain sufficient turgor pressure in the growing zone for leaf elongation. The slower decrease in LE, LWC, and leaf $\Psi_{w}$ for Atlas fescue during the drought-stress period suggested its greater drought tolerance and the potential value for improving this characteristic in a breeding program.

\section{Literature Cited}

Aussenac, G., P. Grieu, and J.M. Guehl. 1989. Drought resistance of two Douglas fir species (Pseudotsuga menzeisii (Mirb.) Franco and Pseudotsuga macrocarpa (Torr.) Mayr.): Relative importance of water use efficiency and root growth potential. Ann. Sci. For.

Begg, J.E. and N.C. Turner. 1976. Crop water deficits. Adv. Agron. 28:161-217.

Boyer, J.S. 1982. Plant productivity and environment. Science 218:443-448.

Boyer, J.S. 1988. Cell enlargement and growthinduced water potentials. Physiol. Plant. 73:311-316. 46(Suppl.):384-387.
Carrow, R.N. 1996. Drought resistance aspects of turfgrasses in the Southeast: Root-shoot responses. Crop Sci. 36:687-694.

Cregg, B.M. 1995. Plant moisture stress of green ash in contrasting urban sites. J. Arborcult. 21:271-276.

Fry, J.D. and J.D. Butler. 1989. Response of tall and hard fescue to deficit irrigation. Crop Sci. 29:1536-1541.

Graves, W.R., M.A. Koggel, and M.P. Widriechner. 2002. Photosynthesis and shoot health of five birch and four alder taxa after drought and flooding. J. Environ. Hort. 20:36-40.

Hsiao, T.C. 1973. Plant responses to water stress. Annu. Rev. Plant Physiol. 24:519-570.

Huang, B. 2001. Nutrient accumulation and associated root characteristics in response to drought stress in tall fescue cultivars. HortScience 36:148-152.

Huang, B. and H. Gao. 1999. Physiological responses of diverse tall fescue cultivars to drought stress. HortScience 34:897-901.

Jones, M.M., N.C. Turner, and C.B. Osmond. 1981. Mechanisms of drought resistance, p. 15-37. In: L.G. Paleg and D. Aspinall (eds.). Physiology and biochemistry of drought resistance in plants. Academic Press, Sydney.

Kim, K.N., R.C. Shearman, and T.P. Riordan. 1999. Top growth and rooting responses of tall fescue cultivars grown in hydroponics. Crop Sci. 39:1431-1434.

Levitt, J. 1972. Responses of plants to environmental stresses. Academic Press, New York. 697 p.

Marlatt, M.L., C.P. West, M.E. McConnell, D.A. Sleper, G.W. Buck, J.C. Correll, and S. Saidi. 1997. Investigations on xerophytic Festuca spp. from Morocco and their associated endophytes. In: C.W. Bacon and N.S. Hill (eds.). Neotyphodium/grass interactions. Plenum Press, New York.

Matyssek, R., S. Maruyama, and J.S. Boyer. 1988. Rapid wall relaxation in elongating tissues. Plant Physiol. 86:1163-1167.

McCully, M.E. 1999. Roots in soil: unearthing the complexities of roots and their rhizospheres. Annu. Rev. Plant Physiol. Plant Mol. Bio. 50:695-718

McWilliam, J.R. 1968. The nature of the perennial response in Mediterranean grasses. II. Senescence, summer dormancy and survival in $\mathrm{Pha}$ laris. Aust. J. Agr. Res. 19:397-409.

Norris, I.B. and H. Thomas. 1982. Recovery of ryegrass species from drought. J. Agr. Sci. 98:623-628.

Pattanagul, W. and M.A. Madore. 1999. Water deficit effects on raffinose family oligosachharide metabolism in coleus. Plant Physiol. 121:987-993.

Qian, Y.L., J.D. Fry, and W.S. Upham. 1997. Rooting and drought avoidance of warmseason turfgrasses and tall fescue. Crop Sci. 37:905-910

Riga, P. and N. Vartanian. 1999. Sequential expression of adaptive mechanisms is responsible for drought resistance in tobacco. Aust. J. Plant Physiol. 26:211-220.

SAS Institute, Inc. 2003. SAS/STAT, Version 9. User's Guide. Vols. I and II. SAS Institute, Inc., Cary, NC.

Slavik, B. 1974. Direct methods of water content determination, p. 121-156. In: B. Slavik (ed.). Methods of studying plant water relations. Springer-Verlag, Berlin.

Tardieu, F. and T. Simonneau. 1998. Variability among species of stomatal control under fluctuating soil water status and evaporative demand: modeling isohydric and anisohydric behaviours. J. Expt. Bot. 49:419-432. 
Torvert, H.A., J.H. Edwards, and J.F. Pedersen. 1990. Fescues with large roots are drought tolerant. Appl. Agr. Res. 5:181-187.

Wardlaw, I.F. 1969. The effect of water stress on translocation in relation to photosynthesis and growth. II. Effect during leaf development in Lolium temulentum L. Aust. J. Biol. Sci. 22: $1-16$.
Weerathaworn, P., A. Soldati, and P. Stamp. 1992. Anatomy of seedling roots of tropical maize (Zea mays L.) cultivars at low water supply. J. Expt. Bot. 43:1015-1021.

White, R.H., M.C. Engelke, S.J. Morton, and B.A. Ruemmele. 1992. Competitive turgor maintenance in tall fescue. Crop Sci. 32:251256
White, R.H., M.C. Engelke, S.J. Morton, and B.A. Ruemmele. 1993. Irrigation water requirement of zoysiagrass. Int. Turfgrass Soc. Res. J. 7:587-593.

Wu, L. and D.R. Huff. 1983. Characteristics of creeping bentgrass clones (Agrostis stolonifera L.) from a salinity-tolerant population after surviving drought stress. HortScience 18:883-885. 